\title{
Quantificação dos descritores de variedades de soja indicadas para cultivo no Rio Grande do Sul, ano agrícola 2015/2016
}

\section{Quantification of descriptors of soybean cultivars indicated for Rio Grande do Su state, 2015/2016 season}

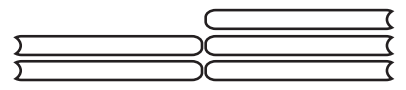

Diógenes Cecchin Silveira ${ }^{1}$

Luiz Pedro Bonetti ${ }^{2}$

Thiago José Copetti Cereser ${ }^{3}$

Rocheli Flores Ceccon ${ }^{4}$

Mogar Waihrich Feijó faccioli ${ }^{5}$

Recibido: mayo 2016 Aprobado: noviembre 2016

\section{Resumo}

A soja é a mais importante oleaginosa cultivada no mundo e uma das principais commodities agrícolas do Brasil, onde representa 49\% da área plantada no país. É uma leguminosa originária do sudoeste asiático, mais precisamente da China. No Rio Grande do Sul constam em registros que 1900 tenha sido o ano primeiro do seu cultivo, porém a difusão exponencial de sua presença na agricultura gaúcha foi alcançada somente a partir dos não 1960. O presente estudo teve como objetivo determinar a distribuição quantitativa e percentual das características fenológicas predominantes nos genótipos de soja indicados pela pesquisa para cultivo no Rio Grande do Sul, no ano agrícola 2015/2016. De acordo com os dados obtidos no presente estudo, foi possível determinar-se que há uma distribuição diversificada das caraterísticas fenológicas dos genótipos indicados para cultivo no Estado, na safra agrícola tratada. Observou-se ainda que os obtentores de soja na região abrangida pelo presente trabalho vêm buscando

1 Graduando em Agronomia, Bolsista PIBIC/UNICRUZ da Universidade de Cruz Alta - Unicruz (diogenessilveira@hotmail.com) Cruz Alta- RS, Brasil.

2 Professor M.Sc da Universidade de Cruz Alta - Unicruz (lbonetti@unicruz.edu.br) Cruz Alta- RS, Brasil.

3 Graduando em Agronomia da Universidade de Cruz Alta - Unicruz (thiagoccereser@hotmail.com) Cruz Alta- RS, Brasil.

4 Graduanda em Agronomia da Universidade de Cruz Alta - Unicruz (rocheliceccon@hotmail.com) Cruz AltaRS, Brasil.

5 Graduando em Agronomia da Universidade de Cruz Alta - Unicruz (mogarfaccioli@hotmail.com) Cruz AltaRS, Brasil. 
cultivares de ciclo médio, com plantas de porte médio e hábito de crescimento indeterminado

Palavras chave: Descritores morfológicos, variedades, melhoramento.

\begin{abstract}
Soybean is the most important oilseed crop in the world and one of the main agricultural commodities in Brazil, which represents $49 \%$ of the area, planted in the country, originated in Southeast Asia, specifically China, in Rio Grande do Sul contained in records in 1900 has been the beginnings of its cultivation. This study aims to determine the quantitative and predominant percentage distribution in soybean breeding programs. According to the data obtained in this study, it can be concluded that there is a diverse distribution of the morphological characteristics of the varieties suitable for cultivation in the state of Rio Grande do Sul, in the agricultural year $2015 / 2016$, noting that the breeding programs they are seeking, medium cycle cultivars with mediumsize plants and indeterminate growth habit.
\end{abstract}

Keywords: Morphological descriptors, varieties, improvement.

\title{
Introdução
}

A soja é a mais importante oleaginosa cultivada no mundo e uma das principais commodities agrícolas do Brasil, onde representa $49 \%$ da área plantada no país e sua produtividade representa em torno de $26 \%$ da Balança Comercial do Agronegócio Brasileiro (CONAB, 2011), considerando-se a safra brasileira de 2009/2010, a cultura obteve crescimento produtivo de cerca $20 \%$, influenciado principalmente pelo aumento de área, de praticamente dois milhões de hectares, em relação à da safra anterior (Conab, 2011).

O Brasil, no ano de 2011 era o segundo maior produtor mundial de soja, com uma produção de 68,5 milhões de toneladas, sendo menor que a dos Estados Unidos, que era de 91,4 milhões de toneladas (FAO, 2011), a produtividade de soja brasileira na safra 2010 foi de $2.941 \mathrm{~kg} / \mathrm{há}$ (IBGE, 2011).

A soja (Glycine max L. Merrill), é uma leguiminosa originária do sudoeste asiático, mais precisamente da China, no Rio Grande do Sul constam em registros que em 1900 tenha sido o princípio do seu cultivo (BONETTI, 1987). Porém, apenas a partir da década de 1930 ocorreu a grande ampliação como cultura produtora de grãos (CAMARA, 2011). 
Segundo Santos et al (2004), a soja é considerada a mais rica leguminosa, pois além de conter todos os aminoácidos essenciais à vida humana, sendo composta por cerca de $40 \%$ de proteína, isoladamente é a fonte protéica mais barata existente, superando a carne (12,5\% mais cara), leite (20\% mais cara) e ovos (25\% mais cara). É parte do desenvolvimento de um amplo complexo agroindustrial, além de ser uma commodity, uniforme e padronizada, podendo ser produzida e negociada por produtores de vários países (Hirakuri e Lazzarotto, 2011).

Segundo Neto et al. (2009), as características da espécie possibilitaram uma grande expansão, como: grande adaptação ao solo, inclusive aos de baixa fertilidade, melhorando com o passar dos anos, possibilidade de mecanização total da cultura, boa adaptação ao sistema plantio direto, grande perspectiva do uso direto da soja na alimentação humana e incentivos fiscais.

Ao revisar princípios básicos, potencialidades e limitações do uso de descritores e marcadores moleculares na identificação de variedades, Milach (1999) observou que os principais tipos de descritores disponíveis para o melhoramento de plantas são os morfológicos, os de proteínas e enzimas, e os de DNA.

A primeira legislação que garantiu os direitos dos obtentores de novas variedades vegetais no Brasil, a Lei no 9456, foi promulgada em 25 de abril do ano de 1997, sendo regulamentada pelo Decreto no 2366 em 5 de novembro do mesmo ano. Essa Lei também criou, juntamente ao MAPA - Ministério da Agricultura, Pecuária e Abastecimento, o SNPC - Serviço Nacional de Proteção, a quem é atribuída a competência pela proteção de cultivares no País. Em razão dessa lei sancionada em 1997 o melhoramento genético no Brasil teve maior valorização. A proteção dos direitos intelectuais sobre uma cultivar se efetua mediante obtenção de um certificado de proteção concedido pelo Serviço Nacional de Proteção de Cultivares - SNPC (SNPC, 2008). Para que uma variedade seja protegida, é necessário que esta seja homogênea, uniforme, distinta e estável. A diferenciação das cultivares é realizada por meio de descritores que, de acordo com a Lei, são características fisiológicas, bioquímica, morfológicas, ou moleculares que sejam herdadas geneticamente (BRASIL,1997).

Diante dos argumentos expostos, o presente estudo tem como objetivo determinar a distribuição quantitativa e percentual dos caracteres fenológicos predominantes nos genótipos de soja indicados para cultivo no Rio Grande do Sul, no ano agrícola 2015/2016. 


\section{Metodologia}

O trabalho constou da compilação das informações que caracterizam as variedades de soja adaptadas e indicadas para cultivo no Estado do Rio Grande do Sul e que estão disponíveis no ano agrícola 2015/2016.

A começar dessas informações, foi determinada, a distribuição quantitativa e percentual, das características desses genótipos. Para essa determinação, foram utilizados os dados constantes em indicações técnicas, folders, folhetos informativos, boletins técnicos ou outros quaisquer meios de divulgação, impressos ou digitais, mantendo-se as descrições fornecidas pelos obtentores das cultivares. A caracterização agromorfológica das cultivares foi feita através de alguns dos descritores varietais, estes já previstos pelo Serviço Nacional de Proteção de Cultivares (SNPC), do Ministério da Agricultura e do Abastecimento, sempre que disponíveis, os quais foram:

I. Cor do hipocótilo: nas cores verde, roxa;

II. Hábito de crescimento: determinado, indeterminado e sem informação;

III. Cor da pubescência: cinza, marrom clara, marrom;

IV. Cor da flor: branca, roxa;

V. Cor da vagem: marrom clara, marrom escura, preta/cinza escura;

VI. Cor do hilo: amarela, c, marrom clara, marrom, preta, preta imperfeita:

VII. Grupo de Maturação: Super - Precoce, Precoce, Médio, Tardio;

VIII. Porte da planta: Baixo, Médio, Alto.

\section{Resultados e discussões}

As características fenológicas, o número de cultivares e sua quantificação percentual encontram-se detalhados na Tabela 1.

Os resultados indicaram uma predominância de materiais de ciclo médio (44\%) em relação aos demais ciclos de maturação. Esse resultado indicou uma tendência de alteração no predomínio de ciclo de maturação entre os materiais indicados, uma vez que esse resultado difere do obtido por SILVEIRA \& BONETTI (2014), os quais, quantificando 107 variedades de soja, encontraram $40 \%$ das variedades indicadas para cultivo como sendo do ciclo precoce, no ano agrícola de 2013/2014. A mudança de predomínio de ciclo médio sobre o ciclo precoce, de uma safra e outra, contrapõe-se ao preconizado por COSTA \& MANICA (1996) de que, na maioria das vezes, cultivares de soja de ciclo longo inclinam-se a serem mais afetados por doenças, uma vez que permanecem mais tempo expostos às mesmas (COSTA \& MANICA, 1996). 
De acordo com MARCOS FILHO (1986) as variedades que possuem ciclo longo e hábito de crescimento indeterminado, são geralmente mais altos. A esse respeito, os resultados observados neste trabalho apresentaram a característica de porte de planta com $36 \%$ das cultivares quantificadas com estatura de porte médio. Esses resultados diferem dos encontrados por SILVEIRA \& BONETTI (2014), no ano agrícola de 2013/2014, onde 53,8\% dos genótipos eram caracterizados como de porte alto.

\section{Tabela 1}

Distribuição quantitativa e percentual dos descritores e características de 75 variedades de soja indicadas para cultivo no Rio Grande do Sul, safra 2015/2016. UNICRUZ, Cruz Alta, RS 2016.

\begin{tabular}{|c|c|c|c|}
\hline Descritor & Característica & Número de Cultivares & Quantificação \% \\
\hline \multirow{5}{*}{ Ciclo } & Super precoce & 4 & 5,33 \\
\hline & Precoce & 20 & 26,66 \\
\hline & Médio & 33 & 44 \\
\hline & Tardio & 7 & 9,33 \\
\hline & Sem informação & 11 & 14,66 \\
\hline \multirow{4}{*}{ Porte } & Baixo & 8 & 10,66 \\
\hline & Médio & 27 & 36 \\
\hline & Alto & 16 & 21,33 \\
\hline & Sem informação & 24 & 32 \\
\hline \multirow{6}{*}{ Hilo } & Amarelo & 1 & 1,33 \\
\hline & Marrom & 4 & 5,33 \\
\hline & Marrom claro & 24 & 32 \\
\hline & Preto & 14 & 18,66 \\
\hline & Preto imperfeito & 2 & 2,66 \\
\hline & Sem informação & 30 & 40 \\
\hline \multirow{3}{*}{ Hipocótilo } & Verde & 29 & 38,66 \\
\hline & Roxo & 23 & 30,66 \\
\hline & Sem informação & 23 & 30,66 \\
\hline \multirow{4}{*}{ Pubescência } & Cinza & 40 & 53,33 \\
\hline & \begin{tabular}{|l|} 
Marrom claro \\
\end{tabular} & 5 & 6,66 \\
\hline & Marrom & 7 & 9,33 \\
\hline & Sem informação & 23 & 30,66 \\
\hline \multirow{3}{*}{ Flor } & Roxa & 29 & 38,66 \\
\hline & Branca & 23 & 30,66 \\
\hline & Sem informação & 23 & 30,66 \\
\hline \multirow{6}{*}{ Vagem } & Marrom & 7 & 9,33 \\
\hline & \begin{tabular}{|l|} 
Marrom claro \\
\end{tabular} & 3 & 4 \\
\hline & Cinza & 2 & 2,66 \\
\hline & Cinza claro & 2 & 2,66 \\
\hline & \begin{tabular}{|l|} 
Cinza escuro \\
\end{tabular} & 1 & 1,33 \\
\hline & Sem informação & 60 & 80 \\
\hline \multirow{3}{*}{ Hábito } & Determinado & 28 & 37,33 \\
\hline & Indeterminado & 36 & 48 \\
\hline & Sem informação & 11 & 14,66 \\
\hline
\end{tabular}


No que diz respeito à cor do hilo, 32\% dos genótipos apresentaram coloração marrom claro. Para cor do hipocótilo, 38,66\% das variedades quantificadas no presente estudo apresentaram coloração verde, equivalente ao mesmo percentual quantificado para cor da flor, predominantemente roxa. Ainda no que se refere à coloração de pubescência, prenominaram os percentuais de 53,33\% para coloração cinza, sendo que para cor da vagem observou-se um percentual de 9,33 para cor marrom. Para a característica de hábito de crescimento, $48 \%$ das variedades apresentaram hábito indeterminado. Esse resultado permite inferir-se uma provável mudança no processo de seleção por parte dos programas de melhoramento quanto a essa característica, uma vez que, no ano agrícola de 2013/2014, SILVEIRA \& BONETTI (2014), encontraram em 107 variedades quantificadas, $58,5 \%$ de cultivares de hábito de crescimento determinado.

\section{Conclusões}

Considerando os dados obtidos no presente estudo, pode-se concluir que há uma distribuição diversificada das caraterísticas fenológicas dos genótipos indicados para cultivo no Estado do Rio Grande do Sul, no ano agrícola 2015/2016, observando-se que os genótipos tendem a ter predominância ciclo médio, com plantas de porte médio e hábito de crescimento indeterminado.

\section{Referências}

BONETTI, L. P. De Santa a Pecadora... A saga da soja pelos campos do Rio Grande. Passo Fundo - RS: Gráfica - Editora, 1987.

BRASIL. Decreto-lei 9.456 de 28 de Abril de 1997. Lei de proteção de cultivares. Diário Oficial da República Federativa do Brasil, Brasília, DF, 28 de abr. 1997. Seção 1. p79.

CAMARA G. M. S. Introdução ao agronegócio soja. Piracicaba: O Autor, 201128 p.. Disponível em <http://www.lpv.esalq.usp.br/lpv584/584\%20Soja\%20 01\%20- \%20Apostila\%20Texto\%20\%20Agronegocio\%20Soja\%202011. pdf >. Acesso: 20 de Janeiro de 2016.

CONAB - Companhia Nacional de Abastecimento (2011): Acompanhamento de safra brasileira: grãos, terceiro levantamento, dezembro 2011 / Companhia Nacional de Abastecimento. Brasília, Conab. Disponível em: <http://www.conab.gov.br/OlalaCMS/uploads/arquivos/11_12_08_10_58_12_08.pdf>. Acessado em: 03 de janeiro de 2016.

COSTA, J. A; MANICA, I. Cultura da soja. Porto Alegre. 1996. 233p. 
FAO. Food and Agriculture Organization of the United Nations - FAOSTATAgriculture. Disponivel em: <http://www.fao.org/corp/statistics/en/> Acesso em: 26 de janeiro de 2016.

IBGE. Levantamento Sistemático da Produção Agrícola: Rendimento médio - Confronto das Safras de 2010 e 2011. Brasil. Abril de 2011. Brasilia: IBGE, 2011. Disponível em: <http://www.ibge.gov.br/home/estatistica/indicadores/agropecuaria/lspa/lspa_201104_201106.shtm> Acesso em: 26 de agosto de 2016.

MARCOS FILHO, J. Produção de sementes de soja. Campinas: Fundação Cargill, 1986. 86p.

MILACH, S.C.K. Disponibilidade de técnicas moleculares para a identificação varietal. In: Pagliano, Daniel. coord. Calidad genética y sanitaria: un instrumento para la competitividad de la cadena agroindustrial. Montevideo: IICA-PROCISUR. 100p. 1999.

NETO, M.E.F., et al. Seletividade de herbicidas pós-emergentes aplicados na soja geneticamente modificada. Planta Daninha, v. 27, n. 2, Viçosa-SP, 2009.

SANTOS, I. et al.; Eficiência de fungicidas aplicados em diferentes épocas no controle de ferrugem asiática da soja causada por Phakopsora pachyrhizi. Fitopatologia Brasileira, Brasília, v.29, Supl. p.80, 2004.

SILVEIRA \& BONETTI. Quantificação dos descritores de cultivares de soja [Glycine max (l.) Merrill] indicadas para cultivo no Rio Grande do Sul, safra 2013/2014. In: XIX Seminário Interinstitucional de Ensino, Pesquisa e Extensão; XVII Mostra de Iniciação Científica; XII Mostra de Extensão; I Mostra de Pós-Graduação 'Ciência e Sustentabilidade', 2014, Cruz Alta. Anais do XIX Seminário Interinstitucional de Ensino, Pesquisa e Extensão, XVII Mostra de Iniciação Científica; XII Mostra de Extensão e I Mostra da Pós-Graduação, Cruz Alta. Cruz Alta: Unicruz, 2014.

SNPC - Serviço Nacional de Proteção de Cultivares. MAPA - Ministério da Agricultura, Pecuária e Abastecimento. 2008. Disponível em: http:// www.agricultura.gov.br/ Acesso em: 27 de março de 2008.

HIRAKURI, M. H.; LAZZAROTTO, J. J. Evolução e perspectivas de desempenho econômico associadas com a produção de soja nos contextos mundial e brasileiro. 3. ed. - versão eletrônica. Londrina: Embrapa SOJA, 2011. (Documentos, Embrapa Soja, n. 319). 